\title{
UN NOTAL ILLICITANO EN EL TRANSITO DE LA EDAD MEDIA A LA MODERNA*
}

\author{
Ana María Navarro Escolano
}

El reconocimiento de la existencia de una unidad notarial histórica, sancionada al ser aprobado el Anteproyecto de Modificación de los Estatutos de la Unión Internacional del Notariado Latino, que sustituyó la expresión Unidad espiritual de todos los Notariados Latinos, por la de Unidad espiritual del Notariado Latino, que se fundamenta, por encima de las variantes locales o accidentales que se desprenden de cada sistema jurídico, en la independencia de la Institución frente al Estado, en el respeto a la voluntad individual, y en la existencia de unas normas de convivencia que la Institución cobija (1), obliga a la investigación a establecer un sistema científico común de análisis de su documentación.

Partiendo de ello, la investigación ha contemplado la Institución desde tres áreas: el conocimiento de la realidad social a través del documento privado; el estudio de las relaciones entre la Institución y la Jurisprudencia; y la propia historia del Notariado.

* El presente trabajo es el resumen de la Memoria de Licenciatura, dirigida por la Dra. Cabanes Catalá, que se leyó el 5 de diciembre de 1983 en la Facultad de Filosofía y Letras de Alicante, con el título: UN NOTAL ILLICITANO EN EL TRANSITO DE LA EDAD MEDIA A LA EDAD MODERNA: ESTUDIO PALEOGRAFICO Y DIPLOMATICO.

(1) A. MARTINEZ SARRION: El Notariado en la Baja Romanidad. Madrid, Anales de la Academia Matritense del Notariado, tomo XXII, vol. 1, 1978, p. 19. 
Nuestro trabajo se enmarca en este último campo, e intenta ampliar el conocimiento interno de la Institución a través de la Paleografía y la Diplomática.

El haber elegido este campo de investigación obedece, respecto al estudio paleográfico, al hecho de que la mayor parte de los trabajos vienen ciñéndose a la documentación emanada de las Cancillerías Regia y Pontificia. Ello, si bien es lógico, dado que en ellas debe centrarse la "élite" de los escribanos, impide el conocimiento objetivo de la realidad escrituraria de un territorio: el modo en que se producen las hipotéticas irradiaciones formales; la aceptación, o no, de las nuevas influencias, su ámbito territorial y cronológico, etc. Desde este punto de vista, la elección de una documentación privada, en una ciudad alejada de los centros universitarios, procedente de una Institución, en la que el aprendizaje de sus miembros se realiza las más de las veces dentro de las normas más ortodoxas del medioevo, y cuya influencia sobre los escribanos locales habría de ser lógica, cubría ampliamente la intención.

Asimismo, el fundir en un mismo estudio Paleografía y Diplomática proviene de circunstancias tanto internas como externas. Las primeras obedecen a la necesidad de contemplar la escribanía, y por tanto al notario, dentro de una unidad de actuación, que por contra será también la de su formación. Es decir, el documento privado que el notario extiende y valida, es el resultado tanto de una interrelación entre retórica y jurisprudencia, cuanto entre sociedad y cultura. Nos referimos a que un determinado modelo de escritura es en si mismo el producto de toda una serie de circunstancias sociales y culturales que no sólo determinan la forma gráfica, sino que a la par provocan una determinada concepción de la legalidad. Escindir ambos factores, si bien es posible en aras de un estudio cualitativo, podria llevar a perder de vista la visión integral de su autor.

Hacia lo anterior apunta también la elección de un notal como base de trabajo entre las tres variantes de documentación notarial: reebedor, o libro en el que se recogen las primeras notas; protocolo, o colección de documentos en los que las fórmulas se abrevian; y el propio notal, que como fase culminante del proceso notarial, no abrevia las cláusulas y permite un estudio más amplio, a más de la seguridad de la vigencia del compromiso redactado.

Las causas externas, a las que antes haciamos alusión, son varias y su aparición obedece tanto a motivaciones personales, cuanto a históricas o profesionales.

Entre las primeras, la fundamental estaba en el convencimiento de 
que existe en nuestro país una clara contradicción entre el interés suscitado recientemente por esta fuente para los estudios sociales, económicos e incluso antropológicos, y la falta de investigaciones que interrelacionen el protocolo con la legislación de su época, lo que supone extraer de él una mínima parte de su contenido real. En este punto resultaba lógico que lo iniciásemos, tanto desde el enfoque de la escritura como elemento de cultura, cuanto por un análisis exhaustivo de la disposición de elementos en el notal, que permitiese en el futuro establecer paralelos con los formularios que sustentan la labor de Jaume Liminyana, $y$, a través de ellos, con la jurisprudencia de la época.

La elección misma de este notal y no de otro, vino determinada por razones puramente históricas. Los años que median entre 1472 y 1482 son de una importancia extraordinaria para la villa de Elche. En 1472, y tras casi un siglo de ser propiedad feudal de Barcelona, era donada a Don Gutierre de Cárdenas, Duque de Maqueda y Comendador Mayor de la Provincia de León, por los Reyes Católicos, si bien la toma de posesión de la villa no se realizará hasta 1482 (2).

Las consecuencias de este acto van a mediatizar la vida de la ciudad hasta las Cortes de Cádiz en dos vertientes. Por una parte en la propia organización interna de la ciudad y sus relaciones con el señor y la monarquía. De otra en una vertiente jurídica, el denominado Pleito de Reducción a la Corona, que con sus pleitos anejos supone un corpus de actuación legal, desgraciadamente falto de estudios en profundidad. Por contra, a la falta de legajos del período, consecuencia de los avatares que a lo largo de su historia ha sufrido el Archivo Histórico Municipal de Elche, se sumaba la desaparición de las Actas de Consell en el período, y pensamos que de la documentación privada podría extraerse alguna luz.

Por último, y no por su menor importancia, gravitaba sobre el planteamiento de nuestra investigación una razón de índole profesional. Antonio Mestre, en la Conferencia de apertura del I CONGRESO NACIONAL DE ARCHIVEROS Y BIBLIOTECARIOS DE LA ADMINISTRACION LOCAL (Elche, 1981), recogía el sentir de los investigadores al afirmar que se había producido un distanciamiento entre las necesidades de la investigación histórica y los sistemas clasificatorios utilizados

(2) P. RUIZ TORRES: Señores y Propietarios. Cambio social al Sur del Pais Valenciano: 1650-1850. Valencia, Institución Alfonso el Magnánimo, Excma. Diputación Provincial, 1981.

A. RAMOS FOLQUES: Historia de Elche, Elche, Tall. Lepanto, 1970. 
por los Archiveros, anclados en el Reglamento de 22 de noviembre de 1901.

Sobre los datos biográficos del notario, pocas son las noticias que hemos podido recoger, tan sólo las que hacen referencia a su nombramiento y toma de posesión conservadas en los fondos de la Real CanciIlería del Archivo General del Reino de Valencia.

Jaume Liminyana es nombrado notario en 1443 tan sólo para ejercer en el Reino de Valencia (apéndice documental n. ${ }^{\circ} 1$ ), si bien, en su propio notal, se autodenomina notario público para los Reinos de Aragón, Valencia y la ciudad de Orihuela.

En el Archivo Histórico de Orihuela se conservan 11 volúmenes suyos, comprendidos entre los años 1448 y $1482(3)$, si bien no se ha podido localizar la documentación emitida por Liminyana desde su nombramiento hasta esa fecha.

En 1483 se traslada a Elche, aunque los cuatro primeros documentos de su notal aparecen datados en Orihuela. El resto, tan sólo con breves y esporádicas excepciones, aparecen ya redactados en su nueva ciudad, donde seguirá actuando hasta 1488 .

\section{LA ESCRITURA DEL SIGLO XV EN LA CORONA DE ARAGON Y SU REFLEJO EN JAUME LIMINYANA}

A lo largo de la primera mitad del siglo XV se observa, en los Estados de la Corona de Aragón, una continua mutación de las formas gráficas, producto, fundamentalmente, de influencias extranjeras que fueron favorecidas por el expansionismo de la monarquía, lo que dificulta el análisis de la escritura como elemento de cultura.

Cencetti, en este sentido, afirma que ...la ormai infinita e capricciossisima varietà de mani individuali opponi gravi ostacoli al riconoscimento e allo sceveramento dell'esenziale e del non esenziale... (4). No obstante, hemos de tener en cuenta, al margen de consideraciones políticas, el momento en que operamos, es decir, el tránsito de la Edad Media al Renacimiento, y todo cambio cultural lleva aparejada la necesidad de encontrar formas escriptorias que se adapten a los nuevos usos (5).

(3) R. M. BLASCO SERRANO: Los Protocolos Notariales. Alicante, ITEM, n. ${ }^{\circ}$ 5, p. 68.

(4) G. CENCETTI: Lineamenti di storia della scrittura latina. Bologna, Ricardo Patron, 1954, p. 289. 
El cuadro gráfico aragonés comienza a sufrir una clara modificación ya en el primer periodo del siglo XIV. Luisa D'Arienzo destaca la influencia de la escritura bastarda francesa que lentamente va penetrando en Cataluña, fundamentalmente a raíz de los matrimonios de Juan I con princesas francesas (6). La acción de la bastarda se traduce en letras como la "f" y la "S", alargadas y descendentes de la pauta, y que Liminyana utiliza frecuentemente. A la par, el particular trazado de la "d" uncial, con el asta superior replegada sobre sí misma; el contraste de trazos finos y gruesos; y la clara tendencia de inclinación hacia la derecha, son claros síntomas de la pervivencia de esta letra.

Estos rasgos, destacados por Jackson (7), se patentizan claramente en la escritura del notario Liminyana. Ello demuestra que, a pesar de que Luisa D'Arienzo afirme que la bastarda francesa era una cursiva caligráfica que se adaptaba poco a la característica rapidez de la escritura en las escribanías notariales, la influencia existió, si bien este peso puede deberse a las peculiaridades del aprendizaje del común de los escribanos aragoneses.

Posteriormente, con la entronización de Fernando I de Antequera, tras extinguirse la dinastía aragonesa con Martín el Humano, aparecerá un nuevo influjo gráfico, centrado en torno a la escritura usada en Castilla, la cortesana (8), que se manifiesta en la predilección por los trazos amplios y redondos, junto con una tendencia a marcar excesivamente la línea general de abreviación, que en Liminyana se patentiza en la abreviatura « $\bar{q} »$, en la que la línea general aparece marcada con un sólo trazo, sin levantar la pluma del asta descendente de la letra, junto con los trazos envolventes de algunas letras como la «a" o la «e».

Si la bastarda francesa y la cortesana de Castilla inciden en el modo de escribir del siglo XV, el influjo del Renacimiento italiano, primero en las altas capas merced a Alfonso el Magnánimo, y con posterioridad en toda la sociedad, hará que la humanística italiana llegue a dominar el panorama escriturario aragonés. El resultado es esa escritura aguda, y con tendencia a inclinarse hacia la derecha de todos conocida.

Dentro de estas coordenadas, el sistema caligráfico de Jaume Limi-

(5) L. D'ARIENZO: Alcune consideracione sul pasaggio dalla scrittura gotica all'umanistica nella produzione catalana dei secoli XV. Studi di Paleografia e Diplomatica, Padova, CEDAM, 1974, p. 199.

(6) L. D'ARIENZO: Op. cit., p. 203.

(7) D. JACKSON: Histoire de l'ecriture. Paris, Denöel, 1982, pp. 100-101.

(8) L. D'ARIENZO: Op. cit., 204. 
nyana presenta como rasgos propios el uso de la "S" capital al final de la palabra; la utilización del alfabeto mayúsculo capital y, en definitiva, la tendencia a aligerar el trazado, alargar las astas, etc.

\section{Nexos}

En las características generales de la escritura de Liminyana hemos de destacar la limitada existencia de nexos, si bien esto debe entenderse más como una falta de variedad que de utilización.

En este escribano es frecuente el enlace de la «d» con la «e» mediante un repliegue realizado por el ástil de la primera.

También prolonga el trazo de la «e» para iniciar la ejecución de la «s" (dies). De esta forma, el ojo superior de la «S» aparecerá siempre cerrado.

Idéntico es el nexo de la "f» con la "e» (feyta), ya que el trazo que corta el caído de la "f» sirve para iniciar el ojo de la "e».

Respecto de la denominada "S" larga, el segundo trazo puede servir de unión con "a»(Ysabel), "e» (possehien), "i" (situades), "o"(sobre), y "C" (cascun).

Algo similar ocurre con la «t», cuyo segundo trazo se prolonga para ejecutar la «e» (temen), la "r» (trenta), o la "s» (sots).

Se patentiza claramente la presencia de las denominadas Leyes de Meyer (9) que pueden resumirse de la siguiente manera:

1. Tras toda letra que termina en una curva convexa hacia la derecha, no se usa una «r» recta (minúscula), sino la denominada redonda.

2. Si una letra termina en una curva convexa hacia la derecha y la siguiente se inicia con una curva convexa hacia la izquierda, al encontrarse ambas no se escriben separadas, sino que se funden la una en la otra, siendo común el trazo que las une.

3. La "d" es de tipo uncial, con el asta hacia la izquierda, delante de las letras de cuerpo redondo.

(9) W. MEYER: Die Buchstabeuverbindungen in der sogennauten gotischen schrift, publicado en Abhandlungen der Akademie der Wissenschafen in Göttingen, Philologisch-Historische klasse. Neve Folgue Band, 1, 1978, pp. 1-24. Cifr. M.* J. CARBONELL SORIA: Un testamento del siglo XV: Benedicto de Caranyena, Portero Real. Alicante, Anales de la Universidad de Alicante, H." Medieval, 2, pp. 233-238. 


\section{Módulo}

Para estudiar el módulo de la escritura de Liminyana, hemos seguido las instrucciones dadas por Gilissen, por considerarlas más pormenorizadas que las de Mallon. Tomando una página del notal se ha medido la caja de escritura con el siguiente resultado:

altura relativa $=5 \mathrm{~mm}$.

altura absoluta $=5,15 \mathrm{~mm}$.

Idéntica operación hemos realizado con respecto a la anchura de las letras. Se han contado un total de 1.000, que abarcan una extensión de 25 líneas y media. Midiendo la extensión de cada línea y sumándolas con posterioridad nos proporcionará una medida de 2.687 milímetros.

Dividiendo éstos por el número de letras se obtiene la anchura relativa de las mismas:

2.687: $1.000=2,687 \mathrm{~mm}$. = anchura relativa.

El rapport modulaire, objetivo final de este estudio, se obtiene mediante la división de la altura media de la línea $(5,15 \mathrm{~mm}$.), por la anchura relativa de la letra $(2,687 \mathrm{~mm}$. $)(10)$.

Rapport Modulaire $=5,15: 2,687=1,91$ milimetros.

Sistema de abreviaturas medievales y su reflejo en los escritos de Jaume Liminyana

Para intentar llevar a cabo el análisis de los elementos braquigráficos nos hemos basado en el trabajo realizado por Adriano Capelli (11), supuesto que viene siendo considerado como uno de los repertorios de abreviaturas más completo.

A pesar de que todo su análisis se realice sobre abreviaturas latinas e italianas y no haga referencia alguna a las valencianas, hemos considerado lícita la aplicación de su trabajo a cualquier lengua romance, dada la similitud existente en la morfología de las palabras.

En la elaboración de un sistema de abreviaciones, como en todo código lingüístico, no sólo influye, siendo lo principal, el sistema ortográfico

(10) I. GILISSEN: L'expertise des écritures Médiévales. Gand, Editions Scientifiques E. Story-Scientia S.P.R.L., 1973, p. 25.

(11) A. CAPELLI: Dizionario de abbreviature latine ed italiane, (sesta edizione). Milano, Ulrico Hoepli, 1979. 
y aún el fonético, sino también la propia cultura caligráfica. Por ello, si bien el primer pensamiento validaba la traspolación, el seguindo nos ha obligado, a la luz de la propia experiencia, a variar el sistema de Capelli en los siguientes puntos:

1. Signo general: contracción y suspensión.

2. Signos especiales.

3. Letras superpuestas.

4. Modificaciones literales.

Signo general: Contracción y suspensión

Entre los signos generales utilizados, tanto para la contracción simple, cuanto en la mixta, el más usual es una línea, que puede ser recta o curva, aunque en este escribano predomine el trazado rectilíneo, en la parte superior de la palabra abreviada y en paralelo a la misma.

No obstante, este signo general presenta algunas variaciones en las palabras agrupadas en el apartado de abreviaturas por suspensión, que detallaremos en el estudio de las mismas.

Pertenecen al primer grupo las palabras en las que sólo aparecen trazadas la primera y última letra. El notario Liminyana sólo utiliza este tipo en monosílabos $\overline{\mathrm{mu}}$ : meu; o en palabras de procedencia latina: $\overline{o a}$ : omnia.

Lo habitual viene a ser el uso de la contracción mixta, siendo éste uno de los tipos de abreviaturas más empleado:

scia: sciencia.

sglia: sglesia.

En las abreviaturas por suspensión se distinguen varios signos, el primero, lógicamente, el punto. El escribano traza la primera letra de la palabra y coloca este signo a continuación. Liminyana sólo lo utiliza en los vocablos más convencionales: S.R.: Senyor Rey.

Otros signos de suspensión son:

$$
\begin{aligned}
& \text { OB: altre } \\
& \text { naty : nativitate } \\
& \text { noty : notarii }
\end{aligned}
$$

Al amparo de esta pequeña muestra es destacable que estos signos no tienen un significado propio, sino que se usan únicamente para indicar que la palabra está abreviada.

Para terminar constatamos la presencia de lo que anteriormente he- 
mos denominado signo general, como otro indicativo de abreviatura en las demonimadas por suspensión.

\section{Signos especiales}

Al enunciar el cuadro clasificatorio en el que nos hemos basado para este estudio, precisamos que en este apartado incluíamos aquellos signos que tenían tanto un significado propio, como relativo.

Se puede establecer aquí una nueva subdivisión. Por un lado los que no varían de significado a pesar de su posición:

$$
\begin{aligned}
& \mathcal{l}: \text { er, ar } \\
& \text { te : ur, tur } \\
& \text { Zc : rum : etcétera }
\end{aligned}
$$

Por otro, los que dependen de su aposición en el vocablo para tener uno u otro significado. El más conocido es 9 , con un valor de con, com, cun, cum, si está al inicio de la palabra, o bien con valor de us, si aparece al final:

9 querents: conquerents

9 semblants: consemblants

dess 9 : dessus

me 9 : meus

A pesar de que habría varios signos especiales que destacar en la escritura valenciana, Liminyana los reduce a tan sólo tres: el denominado signo general, el signo, con valor constante de quondam; y el $\bar{q}$, cuya lectura es que.

\section{Letras sobrepuestas}

Aun siendo uno de los apartados más amplios que el autor italiano observa, nuestro notario lo reduce a tan sólo tres formas, y siempre en el caso de vocales.

La primera, la aposición de una vocal sobre una consonante, lo que lleva implícito la falta de la letra «r". En Liminyana se reduce a dos letras: la ut» y la «p».

pimerament: primerament

$t^{\mathrm{a}}$ : contra

La segunda, cuando aparece una vocal sobre la letra «q", indica la falta de la «u»: $\stackrel{a}{q}$ : qual. 
El tercer caso sería la colocación de una vocal, que indicaría el final de la palabra, tras el trazado de las primeras letras, ex ${ }^{\circ}$ : execucio.

Modificaciones literales

Denominamos modificaciones literales a aquel grupo de consonantes que, con la aposición de un determinado signo varían su valor fonético. Esta variación es constante e independiente de su aposi ción en la palabra y se limita a tres letras:

$\overline{\mathrm{p}}$ : pre

p: per, par

: pro

q: que

$\beta$ :ser

: sen

A continuación ofrecemos el elenco de las abreviaturas empleadas por Liminyana en el notal analizado. 


\section{A}

$\bar{a}:$ an

absetts: absents

abtamet: abtament

accepte: accepten

accios: accions

aemftots: aempertots

afermamet: afermament

afrontacios: afrontacions

agradab̄s: agradables

âiã: anima

ār: alias

afj: altre

Alaquaãt: Alaquant

albar̃ãs̄: albarans

algũã: alguna

alñs̃: alnes

altr̃̄s: altres

alquria: alquería

Andrũ : Andreu

Antẽã ra: Antequera

Anthō: Anthon

Anthiōi: Anthoni

Anthoni g: Anthonius

añūal: annual

añũãlmẽèt: annualment

añūāls: annuals

Apici: Aparici

apfitar: aprofitar

apilis: aprilis apoq $^{\text {a: }}$ apoqua

apoqs: apoques

a $\overline{P P}$ : apropasat

apparen: apparexen

apparexets: apprexents

aps̃: apres

aqul: aquell

aqlla: aquella

aq̄iles: aquelles

aqsta: aquesta

Aragoñu: Aragonum

$\operatorname{arm}^{2}$ : armer

arredamet: arrendament

arredar: arrendar

arredatores: arrendatores

a $\$$ etis: aseretis

atorgamet: atorgament

atorgare: atorgaren, atorgarem

atribuhit: atribuhint

attendr: attendre

avat: avant

B

Balagur: Balaguer

barbr: barber

baste: basten

Bemmoder: Bememoder, Bemimoder

bns: bens 
$\overline{B n}$ : Bernat

Bnt: Bernat

bof: bon

bonf: bonorum

Brthomu: Berthomeu

\section{C}

cabis: cambis

calcet $^{\boldsymbol{}}$ : calceter

carnic $^{\sim}$ : carnicer

carregamēt: carregament

carts: cartes

cascu: cascun

cascua: cascuna

castay: castany

causs: causes

cautia: cautela

cavallr: cavaller

cinquata: cinquanta

cinqanta: cinquanta

ciutats : ciutatans

cTa: cautela

clausuls: clausules

complidamete: complidamente

complimet: compliment

compare: comprarem, compraren

compt: comprat

compdempnacios: compdemp-

\section{nacions}

condepnada: condempnada

confessare: confessarem, con-

fessaren confesse: confessem, confessen

consentamet: consentament

considerat: considerant

constitucios: constitucions

constituhim 9: constituhimus

constreny ${ }^{\sim}$ : constrenyer

contracts: contractes

conveniedo: conveniendo

copradors: compradors

coss: coses

costums: constumes

cru: creu

cubrts: cuberts

cuig: cuius

cuiuslibt: cuiuslibet

$\checkmark$ dempnà: condempnam

9 dempnada: condempnada

9 ferm: confermen

9 fes: confes

9 fessa: confessa

9 fessen: confessen

9 frotades: confrontades

9 frontades: confrontades

oprar: comprar

9 ptar: comptar

9ptadors: comptadors

9 ptants: comptants

9 sequencia: consequencia

9 sta: consta

9 stumats: constumats

9 suetuts: consuetuts

9 sult: consult

$9^{t^{\mathrm{a}}}$ : contra

9 tenguda: contenguda 
9 tengudes: contengudes

2 tenguds: contengudes

9 tent: content

9 tinença: continença

9 tinent: continent

9 tinuat: continuat

9 tra: contra

9 tractades: contractades

9 tractads: contractades

9 tracte: contracte

9 tracts: contractes

9 trari: contrari

9 venir: convenir

9 venit: convenint

D

d: de

df : dines

damūt: damunt

dass: dans

decembr: decembre

deeset: deesent

defendr: defendre

dei 9 : deius

demaar: demanar

demaat: demanat

demanads: demanades

de $\boldsymbol{F}^{\text {tida: }}$ departida

despesss: despesses

dess 9: dessus

deva: devan

devat: devant deve: devem, deven

devie: deviem, devien

diffinitivs: diffinitives

dins: diners, dines

dis $\overline{c r t}$ : discret

dits: discret

dits: dites

diven $\overline{d r s}$ : divendres

divšes: diverses

dा: del

Dni: Domini

dōa: dona

dōar: donar

dōat: donat

domica: dominica

dompar: dompnar

donara: donaran

donare: donarem, donaren

dons: dones

drap". draper

drits: drets

$\overline{\mathrm{ds}}$ : diners, dines

Dspuig: Despuig è: en

ecclia: ecclesia

eccliastichs: ecclesiastichs

eent: essent

eer: esser

eig : eius

empo: empero 
enga: engan

enseps: ensemps

entvenir: entrevenir

eorf: eorum

e pla: eplistola

cof : etcétera

nf: etcétera

ex : execucio

ex ${ }^{\text {ori }}$ : executori

ex ${ }^{\mathrm{ri}} \mathrm{a}$ : executoria

exame: examen

expir: experir

fadigs: fadigues

fadigus: fadigues

febr ${ }^{N}$ : febrer

ferma: fermam, ferman

fermaceria: fermanceria

fermare: fermarem, fermaren

ferme: fermem, fermen

Ferra: Ferran

Ferradez: Ferrandez

fets: fetes

Fonts: Fontes

formets: forments

Fracischo: Francischo

fracament: francament

fracamet: francament

Francisc 9 : franciscus

Francsch: Francesch

Frañcscha: Francescha franqa: franquea

franqs: franques

\section{G}

G 3r: Guillem

geñal: general

geñalmb : generalment geñalmet: generalment gma: germa

$\mathrm{G}^{\circ}$ : Gonçalvo, Gonçalo

Gomz: Gomez

Goncalvz: Goncalvez

Gostaça: Gostança

govne: governe

grat: gratis

Granyaa: Granyana

guardamet: guardament

Guilābrrf: Guilabert ha: han

hage: hagen

haguessn: haguessen

haguessn: haguessen

hav $^{\sim}$ : haver

havets: havents

havie: haviem, havien

here 9: hereus

hits : habitadors

hitacio: habitacio 
hitador: habitador

hitant: habitant

honof: honorable

hon: honrat

honosf: honorables

huytata: huytanta

Ihs: Ihesus

insolm: insolum

in $\beta$ tes: insertes

instrm: instrument

irrevocab̄; irrevocable

itm: item

\section{I}

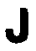

Jac: Jacme

jan $\sim$ : janer

Javaloys: Javaloyes

Joha: Johan

jue 9: jueus

jurametis: juramentis

jurameto: juramento

juramets: juraments

jure: juren

$\overline{\mathrm{Kri}}$ : kalandari larg ${ }^{\circ}$ : largament

libr: libre

librs: libres

licitaet: licitament

Liminyaa: Liminyana

limitacios: limitacions

limitads: limitades

lits: litteris

liurs: liures

loa: loam

loare: loarem

longamet: longament

Lopz: Lopez, Lopiz

Luxa: Luxan

\section{M}

maa: mana

māada: manada

maña: manera

manay: manament

marresa: Manrresa

martinz: Martinez

mat⿱⺈⿵⺆⿻二丨 : matrimoni

mcad: mercader

mcader: mercader

mčrii: mercurii

meg: meus

mentrs: mentres

mesis: mensis

messios: messions 
met $\sim$ metre

meys: menys

mi 9 : mius

mic $^{\sim}$ : micer

migs: miges

milloramet: millorament

miña: minua

Miql: Miquel

mixts: mixtes

mof : moneda

mo: mon

mobls: mobles

Mollor: Monllor

monestii : monesterii

Mos $\beta$ : Mossen

movets: movents

$\overline{\mathrm{mre}}$ : mestre

mest ${ }^{2}$ : mestre

mü: meu

muTrr: muller not $^{\text {ri }}$ : notarii

nг̄a: nostra

n $\overline{r e s}$ : nostres

nrorf: nostrorum

ntre: nostre $\overline{\text { oa: omnia }}$

obligacios: obligacions

obligare: obligarem, obligaren

obligue : obliguem, obliguen

oblio: obligacio

obTo: obligacio

ob $\beta$ var: observar

oibg : omnibus

omium: omnium

op 9 : opus

ordiña 9 : ordinamus

ostaIr: ostaler

ostal $^{2}$ : ostaler

$N^{\circ}$ : Nicolau

nat : Nativitate

nof : nom

p g: pus

no: nom

nōbrada: nombrada

nomenads: nomenades

nōata: noranta

nos: noms

nosaltrs: nosaltres

not : notarii

p'g: prius

pacts: pactes

pagare: pagarem, pagaren

Palomars: Palomares

pau fator: pauperator

pcca: peccunia

f dicti: predicti 
pedre: pendre

pensios: pensions

pertany ${ }^{\sim}$ : pertanyer

pertanyets: pertanyents

plenamet: plenament

plenariamet: plenariament

pluribg: pluribus

$\mathrm{p}^{\mathrm{i} \mathrm{m}^{2}}$ : primer

$p^{i} \mathbf{m} \tilde{a}$ : primera

$p^{i}$ mamet: primerament

pimáment: primerament

pimera: primera

pna: pena

p̃nf: presencia

pincipal: principal

pnt: present

podie: podiem, podien

pō̄ $\bar{r}$ : poder

poguere: poguerem, pogueren

Pomars: Pomares

posseeixe: posseeixen

posseexe: posseexen

possut: possunt

presentads: presentades

preg: preus

prim $^{\wedge}$ : primer

prima : primera

primamet: primerament

principalib 9 : principalibus

principalmet: principalment

privilitgiats: privilletgiats

pronuciat: pronunciat

prū: preu

p̌sent: present puramet: purament

pusca: puscam, puscan

puxe: puxen

pere: prevere

pivilletgi: privilletgi

$f:$ par, per

$f^{\text {a: }}$ para

paire: peraire

paula: paraula

fado: pardo

fe: Pere

Rez: Perez

P feta: Perfecta

pill: perill

Pot: Perot

fftuals: perpetuals

sonals: personals

fsones: persones

$f$ sons: persones

$f$ t: part

$P^{\text {tany: pertany }}$

$f$ tanyets: pertanyents

p tanyera: pertanyeran

pticio: particio

$f^{\text {ticulars: }}$ particulars

$p^{\overline{t d a}}$ : partida

ptidor: partidor

ptineat: pertineat

$q$ tinecies: pertinencies

$f^{\text {tir: partir }}$

pturbats: perTurbants

$f^{\text {tusa: Pertusa }}$

$\$$ cehiran: procehiran

$\$$ cura: procura 
$8^{\text {or: }}$ Procurador

P) : procurador

$\$$ curador: procurador

pcuradors: procuradors

$\$$ curadriu: procuradriu

$\$$ curat: procurat

Pduhir: produhir

$\&$ fit: profit

fitosa: profitosa

$\$$ hibida: prohibida

$\$$ hibits: prohibits

$\$$ mes: promes

4 mesa: promesa

$\$$ messes: promesses

pmet: promet

$\$$ mete: prometem, prometen

8 metem: prometem

\&metent: prometent

Pmetents: prometents

$q^{\text {metere: }} \overline{\text { prometerem, promete- }}$ ren

\& metets: prometents

qmissios: promissions

p $\overline{\mathrm{mt}}$ : promet

$\Phi \overline{\mathrm{ms}}$ : promes

fpassada: propassada

P pi: propi

pia: propia

$\Phi$ pies: propies

pii: propii

ppis: propis

ppossants: propossants

Qrata: prorata
Progue: prorogue

Pseguir: proseguir

q testar: protestar

Qtests: protestes

Q tstacio: protestacio

$\mathbf{Q}^{\text {tstar: }}$ protestar

tstatis: protestatis

$\phi$ tsts: protestes

Qva: prova

$\Phi$ vehir: provehir

\$ vincia: provincia q: que

P: quondam

qis: quals

$q^{\text {als: }}$ quals

$q^{\text {als }}$ sevol: qualsevol

$q^{2}$ ntitat: quantitat

Q'rant: Quirant

qstio: questio

quat ${ }^{n}$ : quatre

quarata: quaranta

quarecia: quarencia

quat: quant

quatrecets: quatrecents

quilibt: quilibet

quitamef: quitament

quntat: quantitat

quons: questions 


\section{R}

rahos: rahons

ratiffiqn: ratiffiquen

rebir: rebre

recitads: recitades

recu far: recuperar

reebr: reebre

reebuds: reebudes

regns: regnes

remetets: remetents

remunâcio: remuneracio

renucia: renuncia

renuciacio: renunciacio

renuciacionibg: renunciacionibus

renuciacios: renunciacions

renúciada: renunciada

renūciam: renunciam

renuciar: renunciar

renuciat: renunciat

renūciare: renunciarem, renun-

ciaren

renucien: renuncien

renunciacios: renunciacions

reqrir: requerir

restat: restant

restituira: restituiran

re $\beta$ vant: reservant

ri 9 : rius

Rof : Rodriguez

romanets: romanents

Roq ${ }^{2}$ mora: Roquamora

$f f:$ sous

$\beta$ a: sera

$\beta \bar{a}$ : seran

sabr: saber

sagramet: sagrament

salvamet: salvament

sart:" sartre

scia: sciencia

$\beta$ e: sere

se 9 : seus

segos: segons

semp ${ }^{2}$ : sempre

sengls: sengles

sepa: sepan

septembr: septembre

sertãment: serterament

sexata: sexanta

sglia: sglesia

singularibg: singularibus

snia: sentencia

snsa: sentencia

so1: son

sog: sous

sobr: sobre

Sotr: Soler

sols: sols, sous

Sony $\sim$ : Sonyer

sqada: sperada

Spança: Sperança

spial: special

spituals: spirituals 
sprals: spirituals

S. R.: Senyor Rey

Stheva: Sthevan

stimacios: stimacions

stranys: stanyes

succesios: succesions

sup $^{\sim}$ : super

supî̀ : superius

supp $^{a}$ : suppra

Bra: Serra

$\beta$ rano: Serrano

$\beta$ vandum: servandum

$\beta$ vei: servei

$\beta$ veis: serveis

vira: servira

vit: servit

$\beta$ vitut: servitut tramet ${ }^{N}$ : trametre

trasportacio: transportacio tremutana: tremuntana

treta: trenta

trs: tres

ts: testes

tof : testes, testichs

univ̌sal: universal univsitat: universitat univsitatis: universitatis uns: unes utrig: utrique utiumg: utriumque

\section{$\mathbf{T}$}

tacits: tacites

tame: tamen

temp 9 : tempus

tene: tene

termes: termens

Terrads: Terrades

testimois: testimonis

thaffulls: thaffulles

thes: thaffulles

torns: tornes

tots: totes

tpss: temps

tra: terra

valencias: valencians

Valncia: Valencia

valnt: valent

valr: valer

veg: veus

vehia: vehina

vehis: vehins

vellut $^{2}$ : velluter

venditorib 9: venditoribus

vene: venem, venen

venere: venerem, veneren

vents: ventes

vi 9 : vius 
viere: vieren

vinets: vinents

Vivs: Vives

$\overline{\mathrm{Vnt}}$ : Vicent

volm: volem

volirra: volrran

vosaltrs: vosaltres

Ximenz: Ximenez

$x$ stia: christia

volutat: voluntat

vires: vostres

vros: vostros

ypoqs: ypoteques

ypoteqs: ypoteques

Yvanyz: Yvanyez 


\section{Estudio diplomático}

En la introducción aludíamos a la serie de factores que determinan la necesidad de llevar a cabo un análisis detallado de la documentación.

La redacción del “instrumentum», manifestación por excelencia de la función notarial, obedece a modelos preestablecidos que aparecen reflejados en los formularios, y varían aún en la misma época en virtud de los diversos negocios jurídicos.

No obstante, las más de las veces es difícil aunar formulario y protocolo notarial. En el caso de Jaume Liminyana por carencia del primero, lo que obliga a proceder al estudio pormenorizado de los documentos que forman los registros notariales para reconstruir directamente el formulario, o fórmulas características de cada momento y tipo documental.

La reconstrucción, desarrollada en una serie de fases, cuyo resultado se plasma en un conjunto de cuadros, se ha realizado siguiendo la ya clásica definición de Sickel (12).

\section{Protocolo inicial}

Invocación

Intitulación

Dirección

Salutación

Texto

Preámbulo

Notificación

Exposición

Disposición

Cláusulas finales

(12) División clásica de los diplomatistas alemanes del siglo XIX y que recogen todos los manuales, entre ellos el de A. GIRY: Manuel de Diplomatique. Reimpresora Burt Franklin, New York, 527 y ss. 


\section{Aprecación \\ Fecha \\ Saludo final \\ Validación}

Hemos elaborado una serie de cuadros en los que constan las partes del documento a excepción de aquellos que previamente no aparecian, introduciendo además pequeñas matizaciones en los casos que el tipo documental lo exigía, como en los testamentos, en los que se ha sustituido notificación por preámbulo, por no utilizarse aquella en estas cartas. Del mismo modo se ha considerado conveniente reflejar la fecha que precede a cada documento. El cuadro básico utilizado es el siguiente:

Data inicial

Invocación

Intitulación

Dirección

Notificación

Exposición

Disposición

Cláusulas finales

Data final: tópica y crónica

Validación: otorgantes y testigos

Sin embargo, el estudio de los documentos se aborda conjuntamente, analizando cada uno de los elementos expuestos en la sistematización, si bien ésta se basa sólo en aquellos tipos de escritura que ofrecen la posibilidad de comparación, sin considerar aquellos negocios jurídicos de poca representatividad: Apocas (52), Cartas matrimoniales y de dote (6), publicaciones (4), testamentos (4), ventas (41) y permutas (4).

Lógicamente, también quedan fuera de esta descripción aquellos documentos que Liminyana comenzó a redactar pero no terminó.

\section{Data inicial}

Su función en la documentación no es otra que la de mantener un orden cronológico en el notal para facilitar una rápida localización del documento deseado.

Consta de los siguientes elementos: día de la semana, del mes, nom- 
bre del mes y año (con la expresión completa: millar, centenas, decenas y unidades). Salvo en contadas ocasiones aparece redactada en latín.

El sistema de datación es el de la Natividad, con la fórmula completa: Anno a Nativitate Domini, si bien puede aparecer Anno Domini, o, simplemente, Anno.

Las formas de expresión encontradas en el notal son las siguientes:

Die mercurii $V I I^{\text {a }}$ mensis decembris, anno a Nativitate domini $M^{\circ}$ CCCC $^{\circ} \angle X X X^{\circ} V^{\circ}$. que expresamos en los cuadros como Xa.

Cuando la misma fórmula aparece redactada en valenciano, la expresión es $\mathrm{Xg}$.

Con la forma primera, pero añadiendo la data tópica, cuando el notal aparece redactado fuera de su lugar habitual de trabajo, las expresiones pueden ser civitate, vila o loco (Xe).

Otras fórmulas pueden ser:

Eodem die et anno (Xb)

lam dictis die et anno $(\mathrm{Xc})$

Suppradictis die et anno (Xf)

Predictis die et anno $(\mathrm{Xh})$

Eodem die (Xi)

La aposición de la data inicial, salvo en este último caso, requiere dos líneas, o tres si se le añade la tópica, perfectamente separadas del tenor documental. Ello, y el hecho de que aparezcan redactadas en latín a diferencia del resto del texto, nos hace pensar que se trata de un elemento de uso exclusivamente profesional, y que no se reflejaría en los originales.

\section{Invocación}

Tan sólo se utiliza en documentos de tipo familiar o de mayor solemnidad que los comerciales, como testamentos, cartas matrimoniales, de dote, pesquisas, etc.

La excepción se refleja en una venta, la número 46, de 26 de diciembre de 1483 , que suponemos se incluye por significar el comienzo de un nuevo año.

$\mathrm{Va}$ iniciando el instrumento y el documento entregado a los otorgan- 
tes es de suponer comenzaría por ella. Se expresa, usualmente, en latín.

Las fórmulas encontradas son:

In Dei Nomine et eius divina gratia ( $\mathrm{Xa})$

In Dei Nomine, amen (Xb)

Nomen Domini invocato et eius divina gratia, amen $(\mathrm{Xc})$

En Nom de Nostre Senyor Deu sia, amen (Xe)

\section{Notificación}

Los documentos que carecen de invocación comienzan invariablemente por ella. Fórmula breve de la que sólo se han detectado tres ejemplos, pero cuyo uso se constata en todos los tipos documentales a excepción de los testamentos:

Sia a tots cosa manifesta $(\mathrm{Xb})$ que es la más usual.

Sapien tots (Xa)

Noverint Universi (Xc)

Por el contexto parece deducirse que Liminyana utiliza la expresión latina para dar mayor solemnidad al documento. tica.

La notificación es una cláusula puramente formal, sin utilidad prác-

\section{Intitulación}

Unida a la notificación mediante la partícula com, suele constar de los siguientes elementos: pronombre, nombre, apellidos, cargo o profesión y lugar de residencia, a los que, como veremos, se pueden añadir algunos datos más.

Los apartados que se han realizado sobre este elemento son:

Pronombre, nombre femenino, nombre del esposo o del padre y vecindario, no figura nunca el apellido y se refleja como (Xa).

Pronombre, nombre, apellidos, cargo o profesión y lugar de residencia, a los que se les puede añadir un adjetivo después del pronombre (discret, honorable, honrat, etc.), o, tras el apellido, las expresiones major, menor o mija de dies $(\mathrm{Xb})$.

Exactamente igual al anterior pero indicando también el nombre de la esposa (Xd). 
Cuando se incluye un cargo de procura, se hace constar también el nombre y apellidos del interesado (Xe).

Otro de los ejemplos que hemos considerado válido destacar es el de la intitulación normal, pero indicando también el nombre del padre del otorgante, posiblemente por tratarse de un ciudadano destacado $\left(\mathrm{XC}_{\mathrm{C}}\right)$.

\section{Exposición}

Su colocación en el texto es inmediatamente posterior a la intitulación. Su función es reflejar los motivos que impulsan a la redacción del documento, bien mediante un relato detallado de hechos precedentes, bien por una serie de cláusulas cortas. A la hora de establecer la clasificación hemos optado por seguir el mismo criterio.

Del primer caso cabe destacar su unión a la intitulación mediante el verbo considerant:

"...Considerant a vos, 10 magnifich (...), fill del magnifich (...), quondam, que haveu feta venda ab mi a la honrada Na (...), muller qui fon del honrat..., etc. (Xa).

La segunda modalidad $(X b)$ puede aparecer o de forma muy simple: «...de grat e de certa sciencia...», o ir adquiriendo una mayor complejidad hasta fórmulas como:

"...de grat e de certa sciencia, ab duy ensemps e cascun de nos per si tengut e obligat per lo tot, no forçats, ni enganats, ans de bon cor e de agradable voluntat, per nos e per tots los nostres, presents e sdevenidors...".

\section{Disposición}

El conjunto de intitulación, disposición y dirección puede ser considerado como el núcleo del documento, dado que son los elementos que to conforman intrinsecamente.

El que ahora analizamos consta de dos cuerpos claramente diferenciados: el verbo dispositivo, que nos indica el negocio jurídico; y el motivo que origina la redacción del instrumento público.

La disposición varia según los tipos de escritura. En las apocas tiene un sentido de reconocimiento de haber recibido las cantidades adeudadas:

«... atorgam, confessam e en bona veritat regonexem a vos (...) que 
nos havets liurat e pagat, e plenariament satisfet en dines comptants a la nostra voluntat, tots aquells..." (Xf).

Esta disposición se repite tipológicamente en los reconocimientos de deuda, si bien con una pequeña variante:

"... atorgam, confesam, e en bona veritat regonexem nos deure a vos $(\ldots) \times$.

En las cartas matrimoniales y de dote, que por su semejanza se catalogan conjuntamente, la disposición adquiere dos matices: «... fahem fer e complir matrimoni en una, en faz e benediccio de Sancta Mare Sglesia..." (Xb), cuando se trata de poner por escrito la promesa matrimonial realizada tanto por contrayentes, cuanto por parientes. La segunda “... faz/fahem donacio...” $(\mathrm{Xg})$, cuando se refiere a la dote misma.

En las cartas de perdón, consideradas también como una tipología familiar, la disposición se presenta: “... remet, perdone, e abso/ch...» (Xc).

En las obligaciones: "... promet em oblich...» (Xd).

En las permutas y ventas, cuyo valor documental desde el punto de vista comercial es el mismo, la disposición es: "...liuram o quasi liuram...", en el primer caso, y en el segundo se añade el verbo venem. Ambas se identifican en los cuadros como Xh.

De las publicaciones hacer notar que el verbo dispositivo adquiere un valor imperativo: «... reques (...) que liga e publique lo dit instrument...» (Xa). Lo mismo sucede en los testamentos donde aparece como: «...faz e orden aquest 10 meu testament...» (Xe).

Así pues, dejando al margen los últimos casos, la disposición tiene un sentido de compromiso del otorgante respecto al receptor, que se representa por la dirección.

\section{Dirección}

Habitualmente incluida en la disposición, los elementos que la integran son los mismos que en la intitulación; pronombre, nombre, apellidos, cargo o profesión y lugar de residencia.

Se suma a ellos la expresión formal de la presencia o no del receptor en el momento de la expedición del documento.

La forma más usual es: «...a vos (...), vehi de la vila de Elig, qui present sots...” $(\mathrm{Xb})$ 
Cuando el receptor no comparece la fórmula utilizada es: «... absent, be axi com si fos present...».

Lógicamente, en testamentos y publicaciones la dirección es múltiple, dado el número de objetos y receptores, por lo que se ha considerado conveniente otorgarle un signo distinto $(X c)$.

En las cartas matrimoniales y permutas, donde los otorgantes son a la vez receptores, la intitulación es la misma que la dirección (Xd).

\section{Cláusulas finales}

Su misión es la de garantizar el cumplimiento del negocio jurídico contenido en la disposición: aceptación, corroboración, obligación, además de las renunciativas, de las de cancelación y el juramento final.

La considerable extensión de algunas de ellas nos ha obligado a reflejar tan sólo su inicio, en tanto las restantes se desarrollan íntegras.

\section{Cláusulas de Aceptación}

Se presentan en tres modalidades:

«... dix que aceptaba la usufructuacio de bens a ella, per lo dit (...) jaguda, e encara en lo dit nom de tudriu e curadriu testamentaria de (...) dix que reebia, e acceptaba la dita tudoria e curaregiment e administracio de aquell a ella jaquida, e per semblant dix que reebia e acceptava la leja a ella per lo dit (...) jaquida, si e segons en lo dit testament per aquell feyt es contengut e declarat..." (Xa)

"...dix que reebia e acceptava aquella ab aquella honor e reverencia ques pertany, oferintse prest en seguir aquella juxta la segua serie e tenor..." (Xb)

"...acceptam, ab tots los pactes, penes, condicions, juraments, etc...» $(\mathrm{Xc})$

\section{Cláusulas de Corroboración}

Su función es la de reafirmar lo contenido en la disposición y su tipología, lógicamente, muy variada.

Los testamentos, generalmente, usan la que sigue

"...requirent a mi, dit notari, que les dites acceptacions e cosses dessus dites scrivis e continuas al peu e consequencia del 
dessus dit testament, e de aquelles lin do e liure acte, e instrument publich fe portant de com offici se pertanyia per guarda $e$ conservacio de son dret, e dret de quis pertanga...» (Xa)

"...aquest es lo meu testament e la mia pus ultima e derrera voluntat, lo qual vull e man que valla per dret de testament..." (Xc)

Una de las más frecuentes es:

«...fahent e instituhent a vos e als vostres, leals authors, guirents e defenedors, e tenguts de ferma e de leal eviccio e guarencia, e de tots dans, etc... $(\mathrm{Xg})$ ».

Puede presentar la variante de los verbos dans e remetents, en lugar de fahent e instituhent.

Por último, la más sencilla, ya que se reduce a tan sólo tres verbos: «...atorgaren, loaren e fermaren...» $(\mathrm{Xf})$

Cláusulas de Obligación

Como su nombre indica reflejan el compromiso formal de los otorgantes de llevar a cabo lo dispuesto en el documento: «... promet em oblich..." (Xa), con las siguientes modificaciones: "promet a vos e als vostres...», y "...prometem la dita venda...».

También detallamos las que reflejan no una obligación propia, sino de los receptores: «... obligam a vos e als vostres...» (Xb), o la variante que aparece en permutas o cambios: "...obligam la una part de nos a l'altra, e l'altra a l'altra..." (Xc)

\section{Cláusulas Renunciativas}

Mediante ellas, el otorgante declina cualquier acción que pudiera emprender en contra de lo acordado y las leyes que pudieran favorecerles: la ley de Divi Adria, furs, dot e sposalici, etc.

Según los tipos documentales pueden ser cláusulas de gran extensión, que generalmente se inician por: "...renunciam a tota excepcio que no puxman dir, possar, ni allegar...» (Xb). Tan sólo existe una variante:

"...e de present renunciem a qualsevol accio, peticio o demanda, o jus agendi civil o criminal que haya empertany contra vos, e bens vostres per la dita causa...» (Xa) 
Mediante ella queda anulado cualquier contrato anterior que entre en contradicción con lo reflejado en la disposición. Se presenta bajo dos modalidades:

"...aquella mane cancellar e anullar, e aquella haja per cassa, vana, nulla e cancellada, e sens neguna força e valor...» (Xa)

$\mathrm{O}$, simplemente: «...man dampnar e cancellar lo dit contracte... (Xb)

Juramento Final

Cuando entre los otorgantes se encuentra una mujer, ésta jura al final del documento, renunciando con ello a una serie de prerrogativas o derechos que la protegen. La fórmula es:

«...In super yo, dita $\mathrm{Na}(. .$.$) jur per Nostre Senyor Deu, e sobre lo$ Senyal de la Creu, e per los seus sants quatre Evvangelis de la mia ma dreta corporalment toquats e jurats, que contra aquesta carta, ni les coses en ella contengudes, no vendre, ni venir fare null temps en tot, ni en part...” (Xa)

También puede presentarse en el supuesto de que el otorgante detentara un cargo de procura.

\section{Validación}

Para evitar la nulidad de un documento se requiere la presencia de los otorgantes, dos testigos como mínimo y el notario. Todos deben firmar al final del mismo el testimonio de su asistencia, y es lo que recibe el nombre de validación.

La suscripción de los otorgantes presenta la siguiente fórmula: “...S(signo)enyal de mi, En (...), damunt dit, qui aquesta carta atorch, lou e ferm.» Sustituyendo en el notal el auténtico signo por una cruz.

Los testigos se reflejan en el documento mediante las siguientes fórmulas:

"De les quals coses foren present per testimonis..." (Xa)

“Testimonis foren presents a les dites coses..." (Xb)

"Testes predicti» $(\mathrm{Xc})$

"Testimonis foren presents ut suppra" (Xg)

O sencillamente: "Testimonis» $(\mathrm{Xf})$ 
En los testamentos varía la expresión de los testigos: “...testimonis foren presents a la confeccio e publicacio del present testament, demants e pregats, coneguts, e nomenats per lo dit (nombre del otorgante)...» (Xd).

Cuando entre los otorgantes aparece una mujer, es necesaria la presencia de testigos en el momento de su firma para dar validez a la misma. Esta puede realizarse el mismo día de la redacción del documento, en día diferente, o ante otro notario.

"E a la ferma e atorgament de la dita $\mathrm{Na}$ (...), qui ferma e atorga, jura e renuncia en la vila de Elig, disabte, tres dies de juliol, del any... (Xe)»

La suscripción del notario no se refleja en el notal, sino en el documento que se entrega a las partes. Del mismo modo, no se incluye en los documentos transcritos la auténtica firma del otorgante o testigos, sino que se sustituye por un signo convencional. 



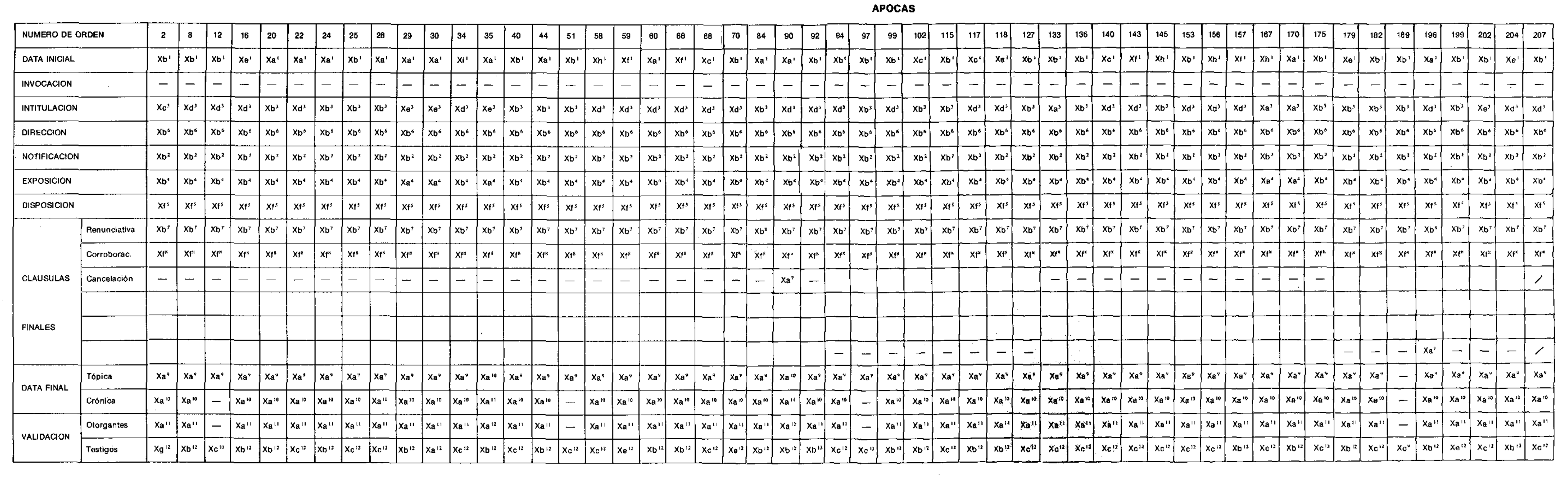




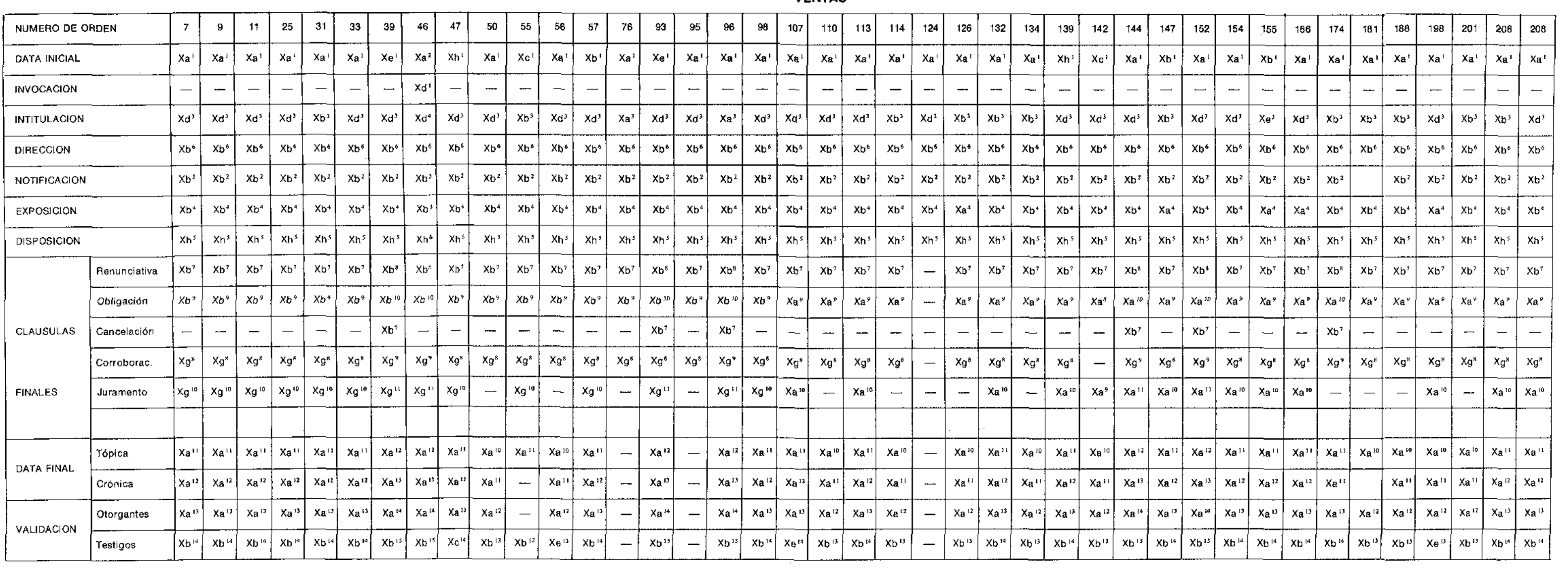





\section{PERMUTAS}

\begin{tabular}{|c|c|c|c|c|c|}
\hline \multicolumn{2}{|c|}{ NUMERO DE ORDEN } & 27 & 91 & 116 & 141 \\
\hline \multicolumn{2}{|l|}{ DATA INICIAL } & $\mathbf{X a}{ }^{1}$ & $X_{a}{ }^{\prime}$ & $X_{a^{\prime}}$ & $x_{a}{ }^{\prime}$ \\
\hline \multicolumn{2}{|l|}{ INVOCACION } & - & - & - & - \\
\hline \multicolumn{2}{|c|}{ INTITULACION } & $x b^{3}$ & $x d^{3}$ & $x d^{3}$ & $x d^{3}$ \\
\hline \multicolumn{2}{|l|}{ DIRECCION } & $X d^{6}$ & $x d^{6}$ & $X d^{6}$ & $x d^{6}$ \\
\hline \multicolumn{2}{|c|}{ NOTIFICACION } & $x_{b^{2}}$ & $x b^{2}$ & $x b^{2}$ & $x b^{2}$ \\
\hline \multicolumn{2}{|l|}{ EXPOSICION } & $x b^{4}$ & $x b^{4}$ & $x b^{4}$ & $x b^{4}$ \\
\hline \multicolumn{2}{|l|}{ DISPOSICION } & $X n^{5}$ & $X h^{5}$ & $\mathrm{Xh}^{5}$ & $x h^{5}$ \\
\hline \multirow{4}{*}{ CLAUSULAS } & Renunciativa & $x b^{7}$ & $x_{b^{7}}$ & $x_{b^{7}}$ & $\mathbf{X} \mathbf{b}^{7}$ \\
\hline & Obligación & $X c^{8}$ & $X c^{8}$ & $X c^{8}$ & $\mathrm{Xc}^{8}$ \\
\hline & Corroborac. & $X c^{9}$ & - & - & - \\
\hline & Juramento & - & $X a^{9}$ & $\mathrm{Xa}^{9}$ & $\mathrm{Xa}^{9}$ \\
\hline \multicolumn{6}{|l|}{ FINALES } \\
\hline \multirow{2}{*}{ DATA FINAL } & Tópica & $X a^{10}$ & $x a^{10}$ & $x_{a^{10}}$ & $x a^{10}$ \\
\hline & Crónica & $X_{a}{ }^{\prime \prime}$ & $x_{a}{ }^{\prime \prime}$ & $X_{a}{ }^{\prime \prime}$ & $x_{a}{ }^{\prime \prime}$ \\
\hline \multirow{2}{*}{ VALIDACION } & Otorgantes & $X_{a^{12}}$ & $x_{a}{ }^{12}$ & $x_{a^{12}}$ & $x a^{12}$ \\
\hline & Testigos & $x b^{13}$ & $x b^{12}$ & $\mathrm{Xb}^{13}$ & $x^{12}$ \\
\hline
\end{tabular}


CARTAS MATRIMONIALES Y DE DOTE

\begin{tabular}{|c|c|c|c|c|c|c|c|}
\hline \multicolumn{2}{|c|}{ NUMERO DE ORDEN } & 36 & 158 & 159 & 168 & 169 & 192 \\
\hline \multicolumn{2}{|l|}{ DATA INICIAL } & $X_{e}{ }^{\prime}$ & $\mathrm{Xa}^{\prime}$ & $X_{h^{1}}$ & $x_{f}{ }^{\prime}$ & $X_{c}^{\prime}$ & $X_{b^{1}}$ \\
\hline \multicolumn{2}{|l|}{ INVOCACION } & $x b^{2}$ & $x b^{2}$ & $x_{b^{2}}$ & $x b^{2}$ & $X a^{2}$ & $x c^{2}$ \\
\hline \multicolumn{2}{|c|}{ INTITULACION } & $x_{d^{4}}$ & $X_{d^{4}}$ & $X d^{4}$ & $X_{\mathbf{a}^{4}}$ & $X d^{4}$ & $X d^{4}$ \\
\hline \multicolumn{2}{|l|}{ DIRECCION } & $X d^{7}$ & $x b^{7}$ & $X d^{7}$ & $x b^{\prime}$ & $x d^{7}$ & $x d^{7}$ \\
\hline \multicolumn{2}{|c|}{ NOTIFICACION } & $x_{b^{3}}$ & $x b^{3}$ & $x b^{3}$ & $x b^{3}$ & $x b^{3}$ & $x_{b^{3}}$ \\
\hline \multicolumn{2}{|l|}{ EXPOSICION } & $x_{a^{s}}$ & $x b^{5}$ & $x b^{5}$ & $x b^{5}$ & $x b^{s}$ & $x b^{s}$ \\
\hline \multicolumn{2}{|l|}{ DISPOSICION } & $x b^{6}$ & $x b^{6}$ & $x_{b^{6}}$ & $X g^{6}$ & $x b^{6}$ & $\mathrm{Xb}^{6}$ \\
\hline \multirow[b]{3}{*}{ CLAUSULAS } & Obligación & $X c^{8}$ & $\mathrm{Xb}^{9}$ & $X c^{8}$ & $X^{9}{ }^{9}$ & $X c^{8}$ & - \\
\hline & Juramento & $X_{a^{9}}$ & $X a^{10}$ & $X a^{9}$ & $X a^{10}$ & $\mathrm{Xa}^{9}$ & $X_{a^{8}}$ \\
\hline & Renunciativa & - & $x b^{8}$ & 一 & $x b^{8}$ & - & 一 \\
\hline \multicolumn{8}{|l|}{ FINALES } \\
\hline \multirow{2}{*}{ DATA FINAL } & Tópica & $X a^{10}$ & $x a^{1 t}$ & $X_{a}{ }^{10}$ & $X a^{11}$ & $X^{10}$ & $x_{a}{ }^{9}$ \\
\hline & Crónica & - & $x a^{12}$ & $X a^{11}$ & $\mathrm{Xa}^{12}$ & $X a^{11}$ & $X a^{10}$ \\
\hline \multirow{2}{*}{ VALIDACION } & Otorgantes & - & $x a^{13}$ & $x a^{12}$ & $X a^{13}$ & $X a^{12}$ & $x a^{11}$ \\
\hline & Testigos & $x f^{\prime \prime}$ & $x b^{14}$ & $x c^{13}$ & $x b^{14}$ & $x_{c}{ }^{13}$ & $x b^{12}$ \\
\hline
\end{tabular}


PUBLICACION

\begin{tabular}{|c|c|c|c|c|c|}
\hline \multicolumn{2}{|c|}{ NUMERO DE ORDEN } & 78 & 161 & 172 & 184 \\
\hline \multicolumn{2}{|l|}{ DATA INICIAL } & $x_{a^{1}}$ & $x a^{\prime}$ & $X_{a^{1}}$ & $x a^{1}$ \\
\hline \multicolumn{2}{|l|}{ INVOCACION } & - & - & - & - \\
\hline \multicolumn{2}{|c|}{ INTITULACION } & $\mathrm{Xa}^{4}$ & $x b^{3}$ & - & $x_{b^{4}}$ \\
\hline \multicolumn{2}{|l|}{ DIRECCION } & $X c^{s}$ & $x_{c^{5}}$ & - & - \\
\hline \multicolumn{2}{|c|}{ NOTIFICACION } & $\mathrm{Xa}^{2}$ & - & $\mathrm{Xa}^{2}$ & $X_{a^{2}}$ \\
\hline \multicolumn{2}{|l|}{ EXPOSICION } & $\mathrm{Xa}^{4}$ & $x a^{4}$ & $\mathrm{Xa}^{3}$ & $x_{a^{3}}$ \\
\hline \multicolumn{2}{|l|}{ DISPOSICION } & $\mathrm{Xa}^{5}$ & $x^{6}{ }^{6}$ & $X a^{4}$ & $x_{a^{5}}$ \\
\hline \multirow[b]{3}{*}{ CLAUSULAS } & Aceptación & $\mathrm{Xa}^{7}$ & $x b^{10}$ & $\mathrm{Xa}^{\mathrm{s}}$ & $X a^{6}$ \\
\hline & Corroborac. & $X a^{8}$ & $x b^{7}$ & $\mathrm{Xa}^{6}$ & $\mathbf{X a}^{7}$ \\
\hline & & & & & \\
\hline \multicolumn{6}{|l|}{ FINALES } \\
\hline \multirow{2}{*}{ DATA FINAL } & Tópica & - & $x b^{8}$ & - & - \\
\hline & Crónica & - & $X a^{9}$ & - & - \\
\hline \multirow{2}{*}{ VALIDACION } & Otorgantes & - & - & - & - \\
\hline & Testigos & $X a^{9}$ & $x b^{\prime \prime}$ & $x_{a^{7}}$ & $X a^{8}$ \\
\hline
\end{tabular}


TESTAMENTOS

\begin{tabular}{|c|c|c|c|c|c|}
\hline \multicolumn{2}{|c|}{ NUMERO DE ORDEN } & 129 & 163 & 173 & 183 \\
\hline \multicolumn{2}{|l|}{ DATA INICIAL } & $X a^{\prime}$ & $x a^{1}$ & $\mathrm{Xa}^{\prime}$ & $X_{a^{1}}$ \\
\hline \multicolumn{2}{|l|}{ INVOCACION } & $x b^{2}$ & $x b^{2}$ & $x_{b^{2}}$ & $x b^{2}$ \\
\hline \multicolumn{2}{|l|}{ INTITULACION } & $x_{b^{5}}$ & $x a^{5}$ & $x b^{5}$ & $X_{b^{5}}$ \\
\hline \multicolumn{2}{|l|}{ DIRECCION } & $X c^{7}$ & $X c^{7}$ & $X c^{7}$ & $x c^{7}$ \\
\hline \multicolumn{2}{|l|}{ PREAMBULO } & $\mathrm{Xa}^{3}$ & $\mathrm{Xa}^{3}$ & $X a^{3}$ & $x a^{3}$ \\
\hline \multicolumn{2}{|l|}{ EXPOSICION } & $X_{a^{4}}$ & $\mathrm{Xa}^{4}$ & $\mathrm{Xa}^{4}$ & $X a^{4}$ \\
\hline \multicolumn{2}{|l|}{ DISPOSICION } & $X e^{6}$ & $X e^{6}$ & $X e^{6}$ & $x e^{6}$ \\
\hline \multirow[b]{2}{*}{ CLAUSULAS } & \multirow[t]{3}{*}{ Corroborac. } & $X d^{8}$ & $X d^{8}$ & $X d^{8}$ & $X d^{8}$ \\
\hline & & & & & \\
\hline \multicolumn{5}{|l|}{ FINALES } & \\
\hline \multirow{2}{*}{ DATA FINAL } & Tópica & $\mathrm{Xa}^{9}$ & $X a^{9}$ & $\mathrm{Xa}^{9}$ & $X a^{9}$ \\
\hline & Crónica & $X a^{10}$ & $X a^{10}$ & $X a^{10}$ & $X a^{10}$ \\
\hline \multirow{2}{*}{ VALIDACION } & Otorgantes & $x a^{11}$ & $\mathbf{X} \mathbf{a}^{11}$ & $x_{a}{ }^{\prime \prime}$ & $X a^{11}$ \\
\hline & Testigos & $X d^{12}$ & $X d^{12}$ & $x d^{12}$ & $X d^{12}$ \\
\hline
\end{tabular}




\title{
Nombramiento como notario de Jaume Liminyana, natural de Orihuela para que pueda ejercer su actividad en el Reino de Valencia
}

\author{
A.R.V. Real Cancillería, n. ${ }^{\circ} 26$, fol. 84 v
}

Similis carta notarie per regnum Valencie, tantum fuit concessa per dictam serenissimam dominam reginam locum tenentem generalem predicta lacobo de Liminyana, oriundo civitate Oriole, que data fuit in civitate Valencie quinta die aprilis anno a Nativitate Domini millesimo quadringentesimo quadragesimo tercio, regnique dicti domini regis Sicilie citra Farum anno nono, aliorum vero regnorum anno XXVIII Falco.

Raymundus Baiuli, mandato domine regine facto per regentem Cancilleriam et examinatus per Guillem Bernardi Caburgada, et per me fuit repertus suficiens.

Probata.

\section{Juramento de Jaume Liminyana como notario}

\section{A.R.V. Real Cancillería, n. 26 , fol. $84 v$}

Die sabbati sexta die aprilis, anno $\mathrm{M}^{\circ} \mathrm{CCCC}{ }^{\circ} X X X X 111^{\circ}$ in Valencie.

Prelibatus lacobus de Liminyana, notarius novites creatur per dictum regnum Valencie tamen per dictam serenissimam dominam reginam locum tenentem generalem predictam convenit et promisit quod pro aliquo delicto sive crimini per eum comisso vel eciam comittendo quod deus a veritat non recurret.

(13) Ante la imposibilidad de ofrecer el total de documentos transcritos, se ha optado por la elección de aquellos que consideramos más representativos: el nombramiento y toma de posesión del notario, uno de tipo comercial (apoca), uno familiar (carta de perdón), y una pesquisa. 


\title{
1483, octubre 30. Elche
}

\section{APOCA. Johan Pastor, como procurador de Gil Gonçalvez, reconoce haber recibido de Caat Sarria, 204 sueldos por el Derecho General de la Sal, por parte de las 136 casas de la Morería de Elche}

\author{
A.H.M.E. Protocolos Notariales, n. ${ }^{\circ} 8$, fol. 46 y $46 \mathrm{v}$
}

Die jovis $X X X^{a}$ (trigesima), mensis octobris, / anno a Nativitate Domini $M^{\circ}$ (millesimo) $\mathrm{CCCC}^{\circ}$ (quadragentesimo) LXXXII! (octogesimo tercio) /

Sia a tots cosa manifiesta, com yo, En Johan $/^{3}$ Pastor, vehi de la vila de Ayora, en nom e axi / com a procurador constituhit del magnifich En Gil / Gonçalvez, vehi de la dita vila, senyor del Dret del $/{ }^{6}$ General de la Sal, dels tachats e avenguts del riu / de Chucar, en ca havent poder complit, e plenera / facultat per la dita mia procuracio, de fer e atorgar $/^{9}$ les coses davall scrites, segons de la dita procura / consta e al notari davall scrit es cert per vista e lectura / de aquella, la qual fon feta en la dita vila, a onze $/^{12}$ dies del mes de septembre del any present e deius / scrit mil quatrecents huytanta tres, reebuda closa e sots- / signada de ma e signe del discret En Johan Perez, $/{ }^{15}$ notari, lo qual Dret del General de la Sal, lo dit / En Gil / Gonçalvez \arrenda del magnifich Micer Jaume / Rosell, cavaller e doctor, habitador de la ciutat / ${ }^{18}$ de Valencia, arrendador major del dit dret, segons / consta per contracte de arrendament fet en la dita / ciutat de Valencia a dos dies del mes de janer / ${ }^{21}$ del any mil quatrecents huytanta hu, reebut per lo discret en / Jaume Gisquerol, notari e scriva de la Diputacio, dels / quals dits arrendaments lo dit En Johan Perez, notari, $/^{24}$ ne fa fe en la dita procura, en lo dit nom atorch, / confes, e en bona voluntat regonech (14) a vos, lo / honrat En Caat Sarria, moro e aljama de la ${ }^{27}$ moreria de la dita vila de Elig, qui present sots / quem havets donats, e pagats, e plenariament / satisffets doents quatre sous de moneda reals de $/^{30}$ Valencia, los quals me havets donat e pagat / per lo dit dret del General de la //46v Sal / qui $\backslash$ pertany a pagar als moros de la morería / de la dita vila, per cent trenta cinch casats, o / fochs a raho de hun real per casa o foch, e los $/{ }^{3}$ quals dits doents quatre sous, de vos en $\mathrm{mi}$, en lo dit / nom confes haver hauts, e reebuts en dines / comptants, en dos partides, ço es que en dies passats me donas $/ 6$ cent trenta sous, e en lo jorn de huy setanta / quatre sous en dines comptants, en castellans / d'or, e en reals valencians a la mia voluntat, $/ /^{9}$ en presencia d'En Jaume Tari, major de dies, e dels / notari, e testimonis davall scrits, per que en lo dit nom / renunciem a excepcio de la moneda no nombra- $/^{12}$ da e no comptada, e aquella de vos en mi no ha- / da e no rebuda en la forma sobredita de com dit es, / e a excepcio d'engan, en testimoni de les quals coses, $/{ }^{15}$ en lo dit nom, faz e atorch a vos e

(14) en mi, tachado. 
als vostres, la / present carta de apoca, de fi, e de absolucio, per haverne / memoria en lo sdevenidor.

Feyta carta en la $/{ }^{18}$ vila de Elig, a trenta dies del mes de octubre del any / de la Nativitat de Nostre Senyor, mil quatrecents / huytanta tres.

$\mathrm{S}$ (signo)enyal de $\mathrm{mi}$, En Johan Pastor da- $/{ }^{21}$ munt dit, qui en 10 dit nom aquesta carta atorch / lou, e ferm, los quals dits CCIII (doents quatre) sous, son de la part del any / $M$ (mil) CCCC (quatrecents) LXXX (huytanta) III (tres) $/^{24}$

Testimonis foren presents a les dites / coses, En Johan Cornella, laurador, e En / Gines Cabatero, vehins de la vila de $/{ }^{27}$ Elig.

\title{
1484, noviembre 28. Elche
}

\section{CARTA DE PERDON. Pere Palomares, vecino de Orihuela, perdona a Andrés (sic) Martínez el crimen de adulterio come- tido con Aldonça, esposa del otorgante, con la que huyó a Elche, por haber permitido el regreso de aquélla}

\author{
A.H.M.E. Protocolos Notariales, n..$^{\circ}$, fol. 181-182 v
}

Die lune XXVIII (vigesimo octava) mensis novembris, / anno a Nativitate Domini $\mathrm{M}^{\circ}$ (millesimo) $\mathrm{CCCC}^{\circ}$ (quadragentesimo) LXXX' (octogesimo) $11 \mathrm{II}^{\circ}$ (quarto). I

In Dei Nomine, amen. Sia a tots cosa manifiesta, $/{ }^{3}$ com yo, En Pere Palomares, treginer, ciutada de la / ciutat de Oriola, considerant a vos, En Andres Mar-/ tinez, seller, ciutada de la dita ciutat, comorant a present $/{ }^{6}$ en la vila de Elig, que en dies passats vos vos (sic) ne portas / a la dita e present vila a Aldonca, muller mia, sens volun- / tat e consentiment meu, la qual tro a huy es stada en $/^{y}$ companyia vostra, e en apres entrevenints entre vos e la dita Aldonca, muller mia, e mi, algunes bones e hon- / rrades persones de la present vila nos han concordat e $/ 12$ avengut que la dita Aldonca, muller mia, haja ten- / guda tornar en companyia mia, axi com de present/es tornada en poder meu, sens que per mi no sia fet, ne faça $/{ }^{15} \mathrm{mal}$ ne dan a vos e a aquella, ans yo us haja a remetre / e perdonar a vos, e a aquella del crim que per vos e per aquella / es stat comes en venirse de mon poder ab vos, a la dita $/^{18}$ e present vila, e star en compnyia vostra e encara haja / a renunciar, e renuncie al clam e denunciacio per mi contra / vos e a aquella mesa davant lo Justicia Criminal de la / ${ }^{21}$ dita ciutat, e jatsia per vos haver vos ne portada la dita / Na Aldonca, muller mia, siats tengut e encorregut en / certes penes, axi civils, com criminals, en fur conten- $/{ }^{24}$ gudes, empero considerant que Nostre Senyor Deu perdona a aquells / quil mataren e li faheren tantes injuries, e lexa que / axi com Ell perdona, perdonem nosaltres, e serem perdonats $/{ }^{27}$ d'Ell per tal, mogut per los dits sguarts e respectes, e / seguint la voluntat e manament del dit Nostre Redemptor / Ihesus Christ, e per que Nostre Senyor me perdo mos peccats quant $/^{30}$ ire davant Ell a juhi, e 
entrevenint les dites bones e hon- / rrades persones per los dits sguarts, sens força alguna, ne per / neguna paga ans de ma mera, bona, e spontanea volun- $/^{33}$ tat, e de certa sciencia, remet, perdone, e absolch, e en $/ /^{18}{ }^{1 v}$ aquella millor e pus congrua e abta manera que / puix e deig a vos, En Andres Martínez, seller, e a la dita $\mathrm{Na}$ Aldonca, muller mia, absent axi com si fossets $/{ }^{3}$ present, lo notari infrascrit en nom e loch vostre, e de / tots aquells de qui sera interes, stipulacio reebent del / dit crim per vos comes en portar vos la dita ma muller $/ 6$ de la dita casa mia e poder meu, e de present renuncie / a qualsevol accio, peticio, o demanda, o jus agendi, civil / o criminal que haja empertany contra vos e bens vostres / $/ 9$ per la dita causa, e encara renuncie, abollesch, casse, / anichile, e anulle, e vull que sia abollit, cassat, anichilat, / anullat, e cancellat lo proces de denunciacio, clam, e acusacio $/{ }^{12}$ per mi contra vos fet, e do aquell per nulle, cas e cancellat, / abollit e anichilat, requirent al magnifich Justicia / Criminal de la dita ciutat, o a qualsevol altres offi- $/{ }^{15}$ cials davant los quals es mes lo dit clam e denunciacio, / que lo dit proces de denunciacio, clam, o acusacio, hagen per nulle, cas e va, abollit, anichilat e cancellat, e contra $/{ }^{18}$ vostra persona e bens per causa del dit proces de denunciacio / judicialment, ni en altra manera, no puxa esser procehit, / e mes avant promet em oblich en ma e poder del dit $/^{21} \mathrm{e}$ infrascrit notari que yo ne los meus, ne altre per mi no us / demanare, ne convendre demanaran, ne convendran / a la persona vostra e bens per les rahons e causes damunt $/{ }^{24}$ dites, perdonant vos lo dit crim, per vos contra mi comes, / e qualsevol altres contra mi comessos, e qualssevol / oys, rencors e males voluntats yo haya haut contra $/^{27}$ vos per les rahons damunt dites, impossant a mi e als / meus, per causa del dit crim e delicte fet per vos en portar / vos la dita muller mia e bens, scilenci e callament perpe- $/^{30}$ tual de james no demanar, ne convenir a vos e als / vostres, ne bens vostres, civilment, ne criminal, per la causa damunt dita ne per qualsevol latres requi- $/{ }^{33}$ rent e pregant al dit Justicia o a qualsevol altre $/ /^{182}$ official, devant lo qual per mi es messa la dita denunciacio, / clam o acusacio, que aquella mane cancellar e anuliar, / e aquella haja per nulla, cassa, vana e sens neguna for- $/^{3}$ ça e valor, axi com si aquella contra vos per mi possada / no fos, e si per ventura per mi, o per algun altre en nom / meu, en la vida mia, herets impetit, convengut e de $-/ 6$ manat per les dites rahons, o per qualsevol altres, vull / que yo ni aquells, no sia oyt per alguna cort 0 jutge, $/$ ans me sia donat scilenci e callament perdurable, $/{ }^{9}$ axi com nulls se pora dir e entendre a tot profit e / utilitat vostra, e dels vostres, a les quals coses axi / attendre e complir, oblich mi e tots mos bens e drets $/{ }^{12}$ seents e movents, hauts e per haver en tot loch, e re- / nuncien a tota excepcio que no puxa dir, possar, ni / allegar quel dit perdo, abolicio, e renunciacio e coses da- $/{ }^{15}$ munt dites, no haja fetes ni atorgades, en la forma / sobredita de com dit es, e a excepcio d'engan, e vull / e atorch que si en lo dit contracte de perdo falliran al${ }^{18}$ gunes clausules que a validacio de aquell sien necessa- / ries a util e profit vostre, vull que y sin haudes per possa- / des scrites e continuades, axi com si de mot a mot hi $/{ }^{21}$ fossen scrites e appossades, e si en lo present contracte / hi haura algunes paraules obscures que hagen mester / interpretacio, volem que sien interpretades a tot profit $/{ }^{24}$ e utilitat vostra e dels vostres, e per que les dites coses de / major fermetat se alegren, jur per Nostre Senyor Deu, e so- / bre lo senyal de la Creu, e per los seus sants quatre Evvan- $/{ }^{27}$ gelis de la mia ma dreta corporalment toquats, e / jurats que contra la present carta de perdo, e coses / damunt dites, no vendre ni venir fare null temps, $/{ }^{30}$ en tot ni en part, per alguna 
manera, dret, causa, o / raho, ans aquelles fermes e agradables haure si Deus / me ajud e los seus sants quatre Evvangelis.

Feyta $/^{33}$ carta en la vila de Elig a vint e nou dies del mes $/ /^{182 v}$ de noembre del any de la Nativitat de / Nostre Senyor mil quatrecents huytanta quatre./

S(signo)enyal de mi. En Pere Palomares, damunt dit, $/^{3}$ qui aquesta carta de perdo e coses damunt dites / atorch, lou, e ferm./

Testimonis foren presents a les dites $/{ }^{6}$ coses, Mossen Anthoni d'Oco, prevere, En Perot / Bonet, sartre, vehins de la vila de Elig, e / En Perot Liminyana, mercader, ciutada de $/{ }^{9}$ Oriola.

\title{
5
}

\section{4, junio 22 y 23. Elche}

\section{PESQUISA. Investigación para averiguar el contenido del Sermón de Fray Pedro de León, Bachiller en Teología y Minis- tro del Monasterio de la Texeda, en Santa María. Como testi- gos comparecen Fray Bartolomé de Valdonzellas, prior del Monasterio de la Texeda, constituhido en el Obispado de Cuenca, Johan Quexans, notario, y Mossen Johan d'Ancano.}

\author{
A.H.M.E. Protocolos Notariales, n. ${ }^{\circ} 8$, fol. $133-135$ v
}

Noverint Universi, quod./

Die martis intitulata vicessima secunda, mensis / junii, anno a Nativitate Domini $\mathrm{M}^{\circ}$ (millesimo) $\mathrm{CCCC}^{\circ}$ (quadragentesimo) LXXX (octogesimo) quarto $/^{3}$

En est dia comparech devant la presencia del molt / magnifich Mossen Johan de Luxan, cavaller general, / procurador e batle de la vila de Elig, castell e loch ${ }^{6}$ de Crivillen, per lo molt noble e spectable e egregi / senyor Don Gutierre de Cardenes, Comanador Major / de la provincia de Leon, senyors dels dit vila, castell, $/{ }^{9}$ e loch, lo venerable Fray Bartholome de Valdonze- / Ilas, prior de la casa, orde, e monestir de la Trinitat / de la Texeda constituhit en lo Bisbat de Cuenqua del $/{ }^{12}$ realme de Castella, dient de paraula que en diez / passats, en l'any present mil CCCC (quatrecents) LXXX (huytanta) quatre, lo/ venerable Fray Pedro de Leon, bacheller en Sancta / ${ }^{15}$ Theologia e ministre del dit monestir de la Texeda, / sermona e preyta en la Sglesia de Senyora Sancta / Maria de la dita vila de Elig, la Sancta Crehua- $/{ }^{18} \mathrm{da}$, en lo qual dit sermo dix e prehica, e fon hoyt / dir que les cartes de la butla de la dita Sancta / Crehuada ques donarien per los defunts no les pa- $/{ }^{21}$ gassen fins e tro a tant que les dites cartes fo- / sen liurades aquells que les volguessen pendre, / e que sobre les dites coses reques al dit molt $/{ }^{24}$ magnifich general procurador li plagues fer, / reebre informacio dels testimonis per a provacio de / aquelles, per salvament del dret de quis pertanga $/{ }^{27}$ 
E lo dit / magnifich / general procurador e batle, rebent les / dites coses, si e en tant con de justicia reebre les / pot, e deu, dix que era prest, e apparellat / $/^{30}$ de reebre o fer reebre la dita informacio de testimonis $/ /^{133 v}$ per lo dit Fray Bartholome de Valdonzellas, dessus / requesta, e acomanaba la recepcio dels dits testimonis / a mi, Jaume Liminyana, per aucturitat real notari $/^{3}$ publich, reebedor dels dits actes, que reebes aquella, / la qual yo, dit notari so prest e apparellat / reebre la dita informacio de testimonis de les $/ 6$ persones que lo dit venerable Fray Bartholome / de Valdonzelles, prior, me seran presentades / o devant $\mathrm{mi}$ fetes venir per citacio o en altra $/ /^{9}$ manera./

Testimonis produhits e donats per lo dessus dit / Venerable Fray Bartholome de Valdonzellas / 12 prior, sobre les coses deduhides en la dita / sua requesta, los quals son segons ques / seguexen $/{ }^{15}$

\section{Eodem die / et anno /}

Lo honrat e discret En Johan Quexans, notari, vehi $/^{18}$ de la vila de Elig, testimoni produhit e donat / per lo dit Fray Bartholome de Valdonzellas, qui / jura per nostre Senyor Deu e sobre lo senyal de la Creu $/{ }^{21}$ e per los seus sants quatre Evvangelis, devant / aquell possats e de la sua ma dreta corporal- / ment toquats e jurats, sots virtut del qual $/{ }^{24}$ promes dir veritat de ço que s'abra demanat $/ /{ }^{134} \mathrm{e}$ interogut sera sobre les coses en la dita regesca / contengudes la qual devant li fon lesta, e dili- / gentment donada a entendre singularment, e $/ 3$ distinta segons se pertany e dix que ell, dit testi- / moni, fon en la Sglesia de Senyora Sancta Maria / de la dita vila, dient misa major al poble de la $/{ }^{6}$ dita vila que alli era, ço / es en lo dia de la Asensio (sic) / pus propassada, en lo qual dit dia, lo dit / Venerable Fray Pedro de Leon, sermona e prica $l^{9}$ les butles de la Sacta Crehuada, en lo qual dit / sermo hoy el dit testimoni que dix que les causes / de les indulgencies de la Sancta Crehuada, ço es dels / ${ }^{12}$ morts, no les pagasen aquells que les pendrien, sino / que ans e primerament los fossen liurades les dites / causes.

Interrogat com ho sab, e dix que / de / vista / 15 e presencia.

Interrogat de loch e temps, e de present, e dix / que de loch e de temps ja u ha dit, e de presents $/{ }^{18}$ dix quel dit Venerable Frare Pedro de Leon e ell, / dit testimoni, e moltes gents de la dita vila que / en la dita Sglesia eren a hoyr la dita misa $/^{21}$

Interogat de altres circunstancies al dit feyt / pertanyents, e dix que no./

Dictis die $/{ }^{24}$ et anno /

Lo Venerable Mossen Johan d'Ancano, prevere, comorant / en la vila de Elig, testimoni produit e donat $/{ }^{27}$ per lo dit Venerable Fray Bartholome de Valdon- / zellas, prior dessus dit, qui jura / en mans de frare Miquel / Perez, frare de l'orde de la (1) Maria de la Merçe dels Catius / per Nostre Senyor $/ /^{134 v}$ Due, e sobre lo senyal de la Creu, e per los seus sants / quatre Evvangelis (15) / sots virtut del qual promes dir veritat en $/^{3}$ son testimoni de ço que s'abra demanat, e inte / rrogat / sera / sobre les coses en la dita regesca / contengudes, a qual devant li

(15) devant aquelles posats e de la, tachado. 
fon lesta, e dili- $/ 6$ gentment donada a entendre singularment, e / distinta segons se pertany, e dix que el dit / testimoni fon / present / en la Sglesia de Senyora Sancta $/{ }^{9}$ Maria de la dita vila dient misa major / al poble de la dita vila que alli era lo pri- / mer jorn que sermona e prehica lo dit vene- $/{ }^{12}$ rable Fray Pedro de Leon, ministre dessus dit, / les butles de la Santa Crehuada, en lo qual / dit sermo hoy ell, dit testimoni, que / lo dit Fray / Pedro de Leon, sermonador dix / 15 que els que prenien les butles de morts, que / quant los donasen les cartes de les butles / que pagassen les dites.

Interroguat con ho sab, $/{ }^{18}$ e dix que de vista e de presencia /

Interroguat de loch, e de temps, e de presents, e dix / que de loch, e de temps ja $u$ ha dit dessus, e de $/{ }^{21}$ presents dix quel dit venerable Fray Pedro de Leon / e ell, dit testich, e moltes gents de la dita / vila que en la dita sglesia eren a hoyr la ${ }^{24}$ dita misa.

Interogat de altres circunstancies al dit feyt / pertanyents, e dix que no./

Die mercuri intitulata XXIII (vigesimo tercia), mensis junii, anno $/ /^{135}$ a Nativitate Domini millessimo, quadrigen- / tesimo, octuagessimo quarto./

Comparech devant / la presencia del magnifich Mossen Johan de Luxan, ca- $/^{3}$ valler, general procurador e batle de la vila de Elig, / castell e loch de Crivillen, lo dessus dit venerable / Frare Bartholome de Valdonzellas, prior dessus ${ }^{6}$ dit, e dix de paraula que no enten ne vol donar / mes testimonis dels produhits e donats, per tal / reques al dit magnifich general procurador e batle, que li placia / 9 publicar e manar publicar los dits testimonis / per ell produhits, e donats en la dita causa com / de instrument fer se deja / ${ }^{12}$

E lo dit magnifich general procurador e batle, rebent / les dites coses e en tant com de instruments son reebedors / e attenent a la dita requesta de intrument procehir, mana / ${ }^{15}$ a mi, Jaume Liminyana, / notari /, scriva del dit feyt, que legis / e publicas los dits testimonis, los quals per mi, dit notari, / de continent en presencia del dit magni fich general procurador $\mathrm{e} /{ }^{18}$ batle, e del dit frare Bartholome de Valldonzellas, / los quals per mi, dit notari, foren lests e / publicats aquells, los quals dits testimonis son dessus conti- $/ 21$ nuats e scrits en los dits actes./

E feta publicacio dels dits testimonis, lo dit Fray Bar- / tholome de Valdonzellas, prior dessus dit, reques $/{ }^{24}$ al dit magnifich general procurador e batle de tots los / dessus dits actes e dels dits testimonis li sia manat donar e liurar / acte publich per solventar de son dret e vist $/{ }^{27}$ lo qual per lo dit procurador e batle fon manat a mi, dit / notari que li donas e liuras lo dit acte publich / fe portant /, se- / gons del dit offici se pertany $/^{30}$

Testimonis foren presents a totes les damunt dites / coses, En Luys de // ${ }^{135 v}$ Villena, e Choancho de Vitoria, criats del dit procurador e batle./

Es stat tret acte, e liurat al dit Frare Bar- / tholome de Valdonzellas, prior./

1. devant aquel/s posats, e de la, tachado. 